\title{
Morphological Description of the Flexor Digitorum Accessorius Longus Muscle and its Clinical Significance
}

\author{
Descripción Morfológica del Músculo Flexor Largo \\ Accesorio de los Dedos y su Significancia Clínica
}

\author{
Nicolás Ernesto Ottone, ${ }^{*, * *, * * * * * ;}$; Mariano Tejedor ${ }^{* *}$; Esteban Blasi"**;

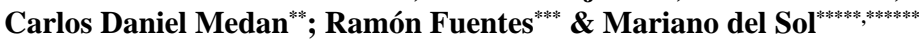

OTTONE, N. E.; TEJEDOR, M; BLASI, E.; MEDAN, C. D.; FUENTES, R. \& DEL SOL, M. Morphological description of the flexor digitorum accessorius longus muscle and its clinical significance. Int. J. Morphol., 33(2):611-619, 2015.

SUMMARY: The flexor digitorum accessorius longus muscle (FDALM) is an anatomical variation that occurs with low frequency in the leg and feet. It was first described by Meckel in 1818. It arises from the tibia or fibula and extends from this towards the quadratus plantae muscle or the flexor digitorum longus muscle, crossing the medial retromalleolar canal and creating a close relationship with the elements of the tibialis posterior neurovascular bundle. A hundred and ten legs were dissected from Caucasian, adult, undefined sex cadavers, previously kept in 5\% formalin solution. We developed a dissection technique in "2 times" to search for and find the flexor digitorum accessorius longus muscle, essential for the safe and successful development of surgical procedures in the region. Three cases of flexor digitorum accessorius longus muscle muscle were described. Two of them were founded in the same cadaver, in a bilateral disposition. Knowledge of this muscle variation, its embryonic origin and the possibility of finding during clinical studies and invasive procedures in the leg and feet is important for differential diagnosis in compressive pathologies.

KEY WORDS: Flexor digitorum accessorius longus muscle; Compressive pathologies; Anatomical variation

\section{INTRODUCTION}

The lower limb bears a significant importance as it allows subjects to move around to perform their daily activities. However, human evolution determines if new morphological structures are originated, or if existing structures are kept, which may cause function disruption or different pathologies in the lower limb.

Anatomical variations in the distal portion of the leg and ankle are infrequent, but if these are present they become important from the morphological point of view and their influence in the clinical sphere (Lewis, 1962; Erickson et al., 1990; Sammarco \& Stephens, 1990; Yüksel et al., 1993; Buckingham et al., 1997; del Sol et al., 2000; Kurtoglu et al., 2001).

The venter of the flexor digitorum accessorius longus muscle (FDALM) originates in the leg, extending through the flexor retinaculum, and is applied to the flexor digitorum longus muscle's and/or quadratus plantae distal tendons. Its insertion is located in on the medial face of the os calcis, below the sustentaculum tali. This muscular anomaly has numerous variables regarding its origin site: tibia, fibula, posterior muscle septum, the leg's fascia profunda, and posterior muscular compartment. There are also variations regarding volume and extension (Turner, 1867; Wood, 1868; Macalister, 1875; Testut, 1884; Driver \& Denison, 1914; Lewis; Nathan et al., 1975; Nidecker et al., 1984; Bergman et al., 1988; Erickson et al.; Sammarco \& Stephens; Buckingham et al.; del Sol et al.; Gümüs,alan \&

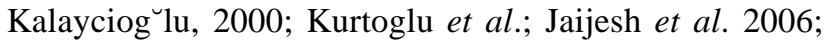
Athavale et al., 2012).

This muscle was first described by Meckel (Testut; Hwang $\&$ Hill, 2009). Subsequent descriptions by other authors were

\footnotetext{
Institute of Morphology J.J. Naón, Faculty of Medicine, Universidad de Buenos Aires, Buenos Aires, Argentina.

** Dissection Team Dr. V.H. Bertone, II Chair of Anatomy, Faculty of Medicine, Universidad de Buenos Aires, Buenos Aires, Argentina.

**** Faculty of Dentistry, Universidad de La Frontera, Temuco, Chile.

***** Doctoral Program in Morphological Sciences, Faculty of Medicine, Universidad de La Frontera, Temuco, Chile.

****** Center of Excelence in Morphological and Surgical Studies (CEMyQ), Universidad de La Frontera, Temuco, Chile.

******** Center of Biomedical Research, Universidad Autónoma de Chile, Chile.
} 
made, both in cadaveric material and live patients: Wood, Testut, Driver and Deninson, Nathan et al., among others. According to these authors, this variation has been reported with different names: accesorium ad calcaneum by Gantzer and Wood, accesorius ad accesorium by Turner, peroneus calcaneus by Turner, accesorius secundus by Humphry, accessorius quadratus plantae (Testut; Turner; Driver \& Deninson; Sooriakumaran \& Sivananthan; Georgiev et al., 2009). According to different research groups, this muscular variation is observed in some primitive mammals, as a posterior compartment muscle of the leg (Jaijesh et al.; Testut; Turner; Nathan et al.).

Though this is the most frequent muscular variation in the leg's posterior region, its occurrence is still unknown by the majority of researchers (Buckingham et al.). Anatomists should not be the only ones interested in this variation: clinicians and surgeons should be interested too due to its possible clinical implication. It becomes essential to describe its morphology correctly: occurrence, relations, and variations (Lewis; Erickson et al.; Sammarco \& Stephens; Yüksel et al.; del Sol et al.; Kurtoglu et al.).

This paper describes three cases of FDALM occurrence. Two of these were found in the same cadaver, and thus considered a bilateral discovery. We have defined its morphology and statistics, compared it to other research works, and finally recognized the importance of this discovery when performing clinical studies and invasive procedures in the patient's legs and feet.
A hundred and ten legs were dissected from Caucasian, adult, undefined sex cadavers, previously kept in $5 \%$ formalin solution.

We developed a dissection technique in " 2 two times" to search for and find the FDALM (Fig. 1). First time:

- Longitudinal incision on the medial side of the lower third of the leg, beginning at the medial malleolus of the tibia, from which extends to cephalic for a distance of about 8 to $10 \mathrm{~cm}$, reaching the upper limit of the lower third of the leg.

- After that, the skin flaps with the subcutaneous tissue are retracted to either sides to expose the deep fascia of the leg. At that level, the fascia is cut to expose the flexor muscles of the leg. It can also be sectioned the posterior intermuscular septum of the leg to allow greater mobilization of the structures in the region.

- After releasing the deep fascia of the leg, we can reach the region of the FDALM, where appear immediately, between the flexor digitorum longus muscle ahead, and the calcaneal tendon behind.

The second time of the dissection technique is related to the visualization of the distal insertion of the accessory flexor muscle of fingers, and will be held as follows (Fig. 2):

- The incision is extended from medial malleolus of the tibia, continuing to the region of the foot, through the flexor retinaculum.

- The skin and the subcutaneous tissue of the flexor

\section{MATERIAL AND METHOD}

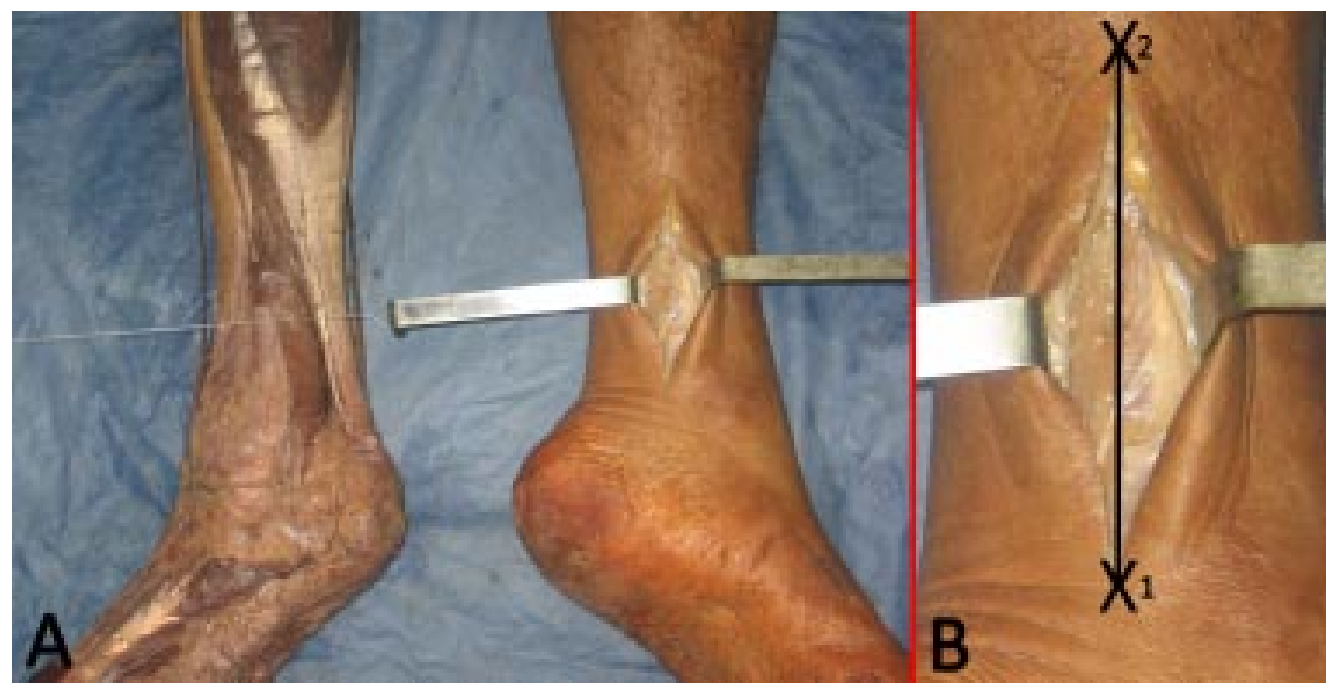

Fig. 1. Dissection technique "1st time". The legs of the figure correspond to the bilateral case. In the left leg was shown the "first time" of the dissection technique. Longitudinal incision: X1 - medial malleolus of the tibia; X2 - upper limit of the lower third of the leg. 


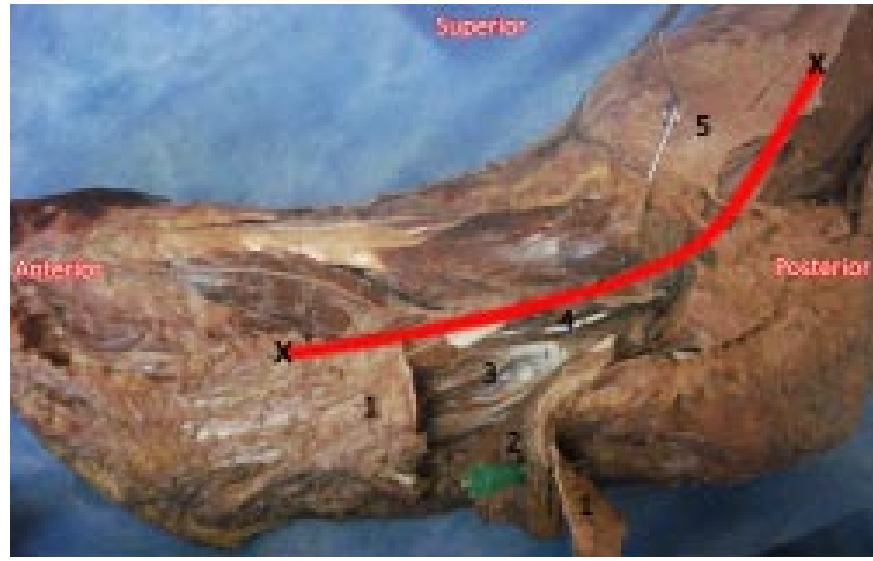

Fig. 2. Dissection technique "2nd time". The "second time" of the dissection technique is applied on the right leg of the bilateral case. 1. Plantar aponeurosis; 2. Flexor digitorum brevis muscle; 3. Quadratus plantae; 4. Distal tendon of the flexor digitorum accessorius longus muscle; 5. Medial malleolus of the tibia.

retinaculum is removed and is cutted, to allow visualization of the insertion of the tendon of FDALM. It shall enter into intimate relationship not only with the tendons of flexor digitorum longus and hallucis longus muscles but also with the neurovascular bundle, and can determine the compression of these neurovascular structures and generate certain pathologies.
- Finally, in the sole, the plantar aponeurosis is cut carefully, by its medial side, immediately below which, the tendon of the FDALM was found. At this level, the FDALM can be fused with the quadratus plantae muscle, as well as with the flexor digitorum longus muscle, according to what type of muscular variation concerned.

\section{RESULTS}

We have found the flexor digitorum accessorius longus muscle in $2.72 \%$ cases; that is, 3 samples in 110 lower limbs dissected. So, taking in account only the bilateral case, we can state that finding this muscular variation in both legs has a $1.81 \%$ occurrence ( 1 case in 55 cadavers). Table I shows our findings, and table II the morphology of ours FDAL muscles.

Unilateral Case (Fig. 3). The muscle has its insertion at the leg, $3 \mathrm{~cm}$ across the lower third of the medial surface of the fibula, at $7 \mathrm{~cm}$ of the lateral malleolus's apex. At its proximal level, the muscle's tendon relates to the flexor digitorum longus muscle in an inferior-medial direction, and to the posterior tibial neurovascular bundle, with the

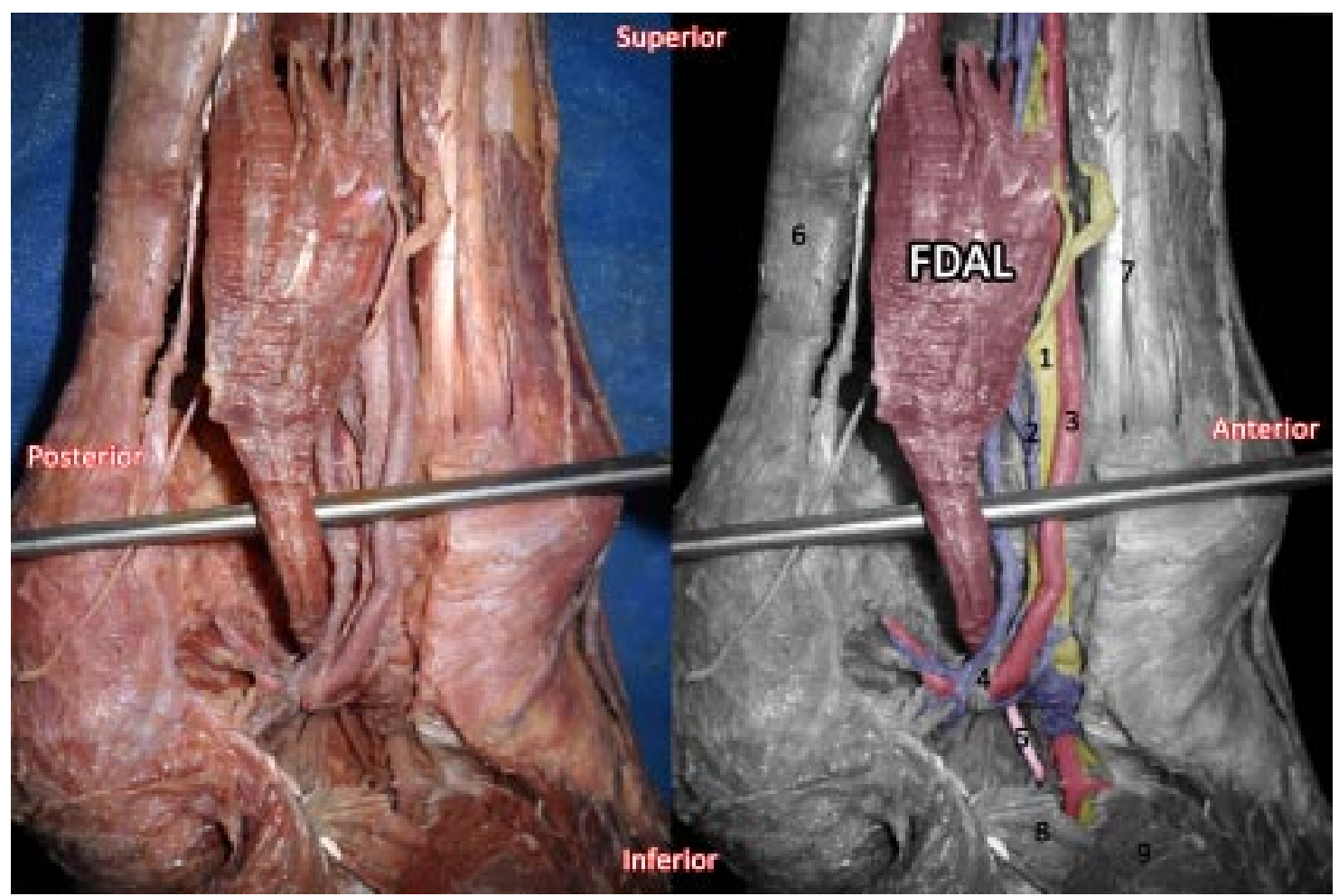

Fig. 3. Unilateral case. FDALM - flexor digitorum accesorius longus muscle; 1. Tibial nerve; 2. Posterior tibial veins; 3. Posterior tibial artery; 4. Relationship between the FDALM and the neurovascular bundle; 5 . distal tendon of the FDALM; 6. Calcaneal tendon; 7. Flexor digitorum longus muscle; 8. Quadratus plantae; 9. Abductor hallucis muscle. 
nerve as its closest element. It is divided into two muscular fascicles - superior and inferior. The first is larger than the second.

It runs down in an inferomedial direction, and reaching the medial retromalleolar region, it relates to this region's elements. The closest and most important element is the tibial nerve, which joins the lateral margin of the FDAL muscle's superior fascicle and passes above the surface of the flexor hallucis longus muscle. Medially, the rest of the elements integrating the neurovascular bundle and the tendons of the flexor digitorum longus and tibialis posterior muscles are observed.

It enters the medial retromalleolar region, applied to its external wall, and related laterally to the tendons of flexor hallucis longus and digitorum longus muscles, and the posterior tibial neurovascular bundle. Inside this canal, each muscular body originates a small tendon that crosses by its deep surface the lateral plantar nerve and corresponding vessels.

In the sole, both fascicles of the FDALM follow the medial margin of the quadratus plantae muscle, and the internal fascicle merges with this muscle. The external fascicle, now aponeurotic tissue, is still to the tendinous portion of the quadratus plantae muscle and ends close to the flexor digitorum longus muscle tendons.

\begin{tabular}{cc}
\hline \multicolumn{2}{c}{ Table I. Our research. n: $110-3$ cases: $2.72 \%$} \\
\hline \multicolumn{2}{c}{ Total AFDL (3 cases, $2.72 \%$ ) } \\
\hline Right Side & Left Side \\
1 case & 2 cases \\
$0.91 \%$ & $1.81 \%$ \\
\hline Unilateral & Bilateral \\
1 case & 1 case \\
$0.91 \%$ & $0.91 \%$ \\
\hline
\end{tabular}

Bilateral Case. Right leg (Fig. 4). The FDALM located on the medial surface of the lower third portion of the leg. Its insertion is located at the tibia's medial margin and at the deep surface of the posterior tibial superficial fascia. This insertion is $6.5 \mathrm{~cm}$ long. The distance between the muscle's superior margin and the medial malleolus base was $8.5 \mathrm{~cm}$.

From its origin at the superior portion of the inferior third of the tibia, it covers the neurovascular bundle. It arises inferior and to the soleus muscle, and runs toward the medial retromalleolar canal, covering the flexor digitorum muscle and the posterior tibialis muscle's tendon.

In the retromalleolar canal, the FDALM forms a muscular arch over the tibial insertion. The neurovascular bundle passes through this arch and then is located in a posterior and internal position towards the posterior tibial bundle. This muscular 'hole' could become a compression site that can cause a pathology that can be compared to the carpal tunnel syndrome in the upper limb. At this point, the tibial nerve is internal to this bundle and relates to the muscle's internal margin, dividing quickly into numerous sensitive branches that reach the region's subcutaneous cellular tissue. At the appex of the medial malleolus and at the superior margin of the adductor hallucis muscle, the muscle quickly becomes a tendon that runs lateral and then anterior and superior to the lateral plantar neurovascular bundle.

Next, the tendon runs between the adductor hallucis muscle medially and the flexor digitorum longus muscle laterally and finally merges to the latter.

In this case, this muscular variation is supplied by calcaneal branches (medialis o lateralis), which are originated directly from the posterior surface of the tibial nerve, between both heads of the gastrocnemius muscle inside the popliteal fossa's inferior triangle. The muscle runs along the posterior tibial neurovascular bundle in a posterior relation until they both reach the soleus's tendinous arch — now it crosses the bundle and is located internal to it.

Table II. Morphology of the flexor digitorum accessorius longus muscle.

\begin{tabular}{|c|c|c|c|}
\hline \multicolumn{2}{|l|}{ Case } & Origin & \multirow{2}{*}{$\begin{array}{l}\text { Insertion } \\
\text { Each fascicle has an independent tendon -medial tendon } \\
\text { ends at quadratus plantae and lateral tendon end at flexor } \\
\text { digitorum muscle }\end{array}$} \\
\hline Unilateral & Case & $\begin{array}{l}\text { Two muscular fascicles (superior and } \\
\text { inferior) - originated from the fibula }\end{array}$ & \\
\hline $\begin{array}{l}\text { Bilateral } \\
\text { side) }\end{array}$ & Case (right & $\begin{array}{l}\text { Unique voluminous muscular body } \\
\text { —originated from the tibia }\end{array}$ & $\begin{array}{l}\text { Unique tendon that merges with the flexor digitorum } \\
\text { longus muscle's tendon }\end{array}$ \\
\hline $\begin{array}{l}\text { Bilateral } \\
\text { side) }\end{array}$ & Case & $\begin{array}{l}\text { Voluminous muscular body formed } \\
\text { by two heads —origin from tibia and } \\
\text { fibula }\end{array}$ & $\begin{array}{l}\text { Unique tendon that merges with the quadratus plantae's } \\
\text { tendon }\end{array}$ \\
\hline
\end{tabular}




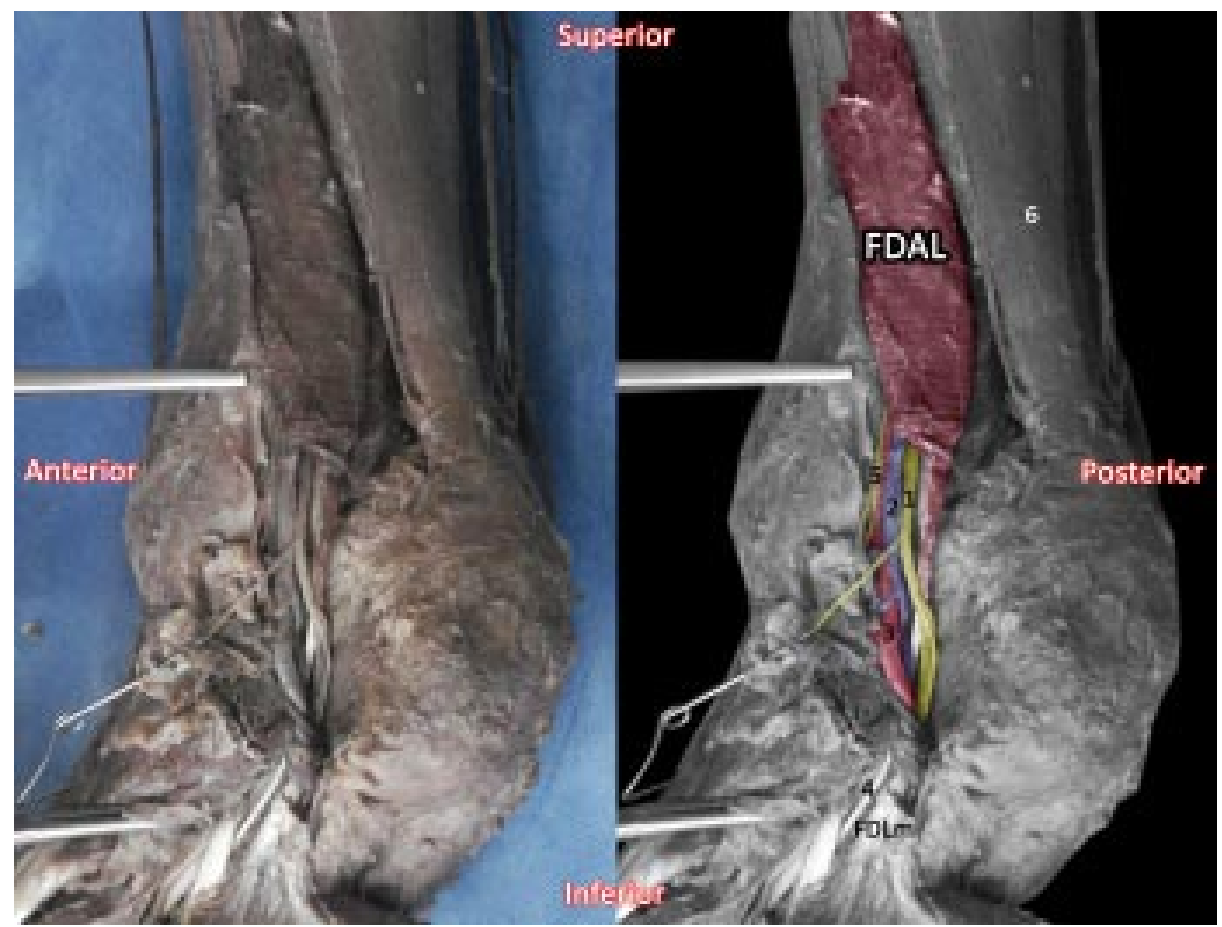

Fig. 4. Bilateral case (right leg). FDALM - flexor digitorum accesorius longus muscle; FDLm flexor digitorum longus muscle; 1 . Tibial nerve; 2. Posterior tibial veins; 3 . Posterior tibial artery;

4. Distal tendon of the FDALM; 5. Branches from the tibial nerve; 6. Calcaneal tendon.

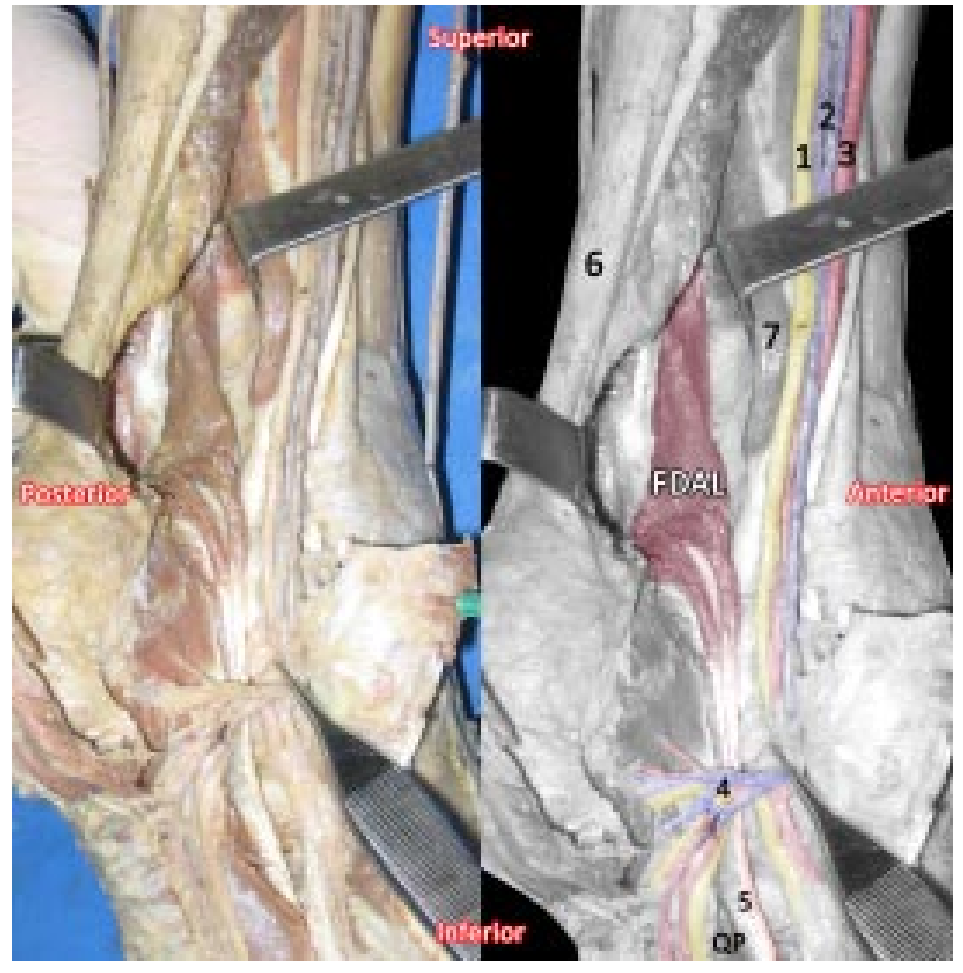

Fig. 5. Bilateral case (left leg). FDALM - flexor digitorum accesorius longus muscle; QP - quadratus plantae; 1. Tibial nerve; 2. Posterior tibial veins; 3 . Posterior tibial artery; 4. Relationship between the FDALM and the neurovascular bundle; 5. Distal tendon of the FDALM; 6. Calcaneal tendon; 7. Flexor digitorum longus muscle.
Left leg (Fig. 5). In this case, the FDALM presented two origins —one originated from the tibia's medial margin and the other from the fibula's medial surface. Originated in the lower third of the leg, both heads quickly merge and form a single voluminous muscular body, which runs towards the sole. This insertion is $5 \mathrm{~cm}$ long. The distance between the muscle's superior margin and the medial malleolus base is 6.5 $\mathrm{cm}$. Before entering the medial retromalleolar canal, the muscular body thins down but is still muscular, and relates to the region's neurovascular bundle by its deep surface, and can in theory compress it when contracting.

It has a short itinerary inside the medial retromalleolar canal, and immediately becomes a thin tendon. Once in the foot, this tendon is located medial to the quadratus plantae muscle, and merges with it. 


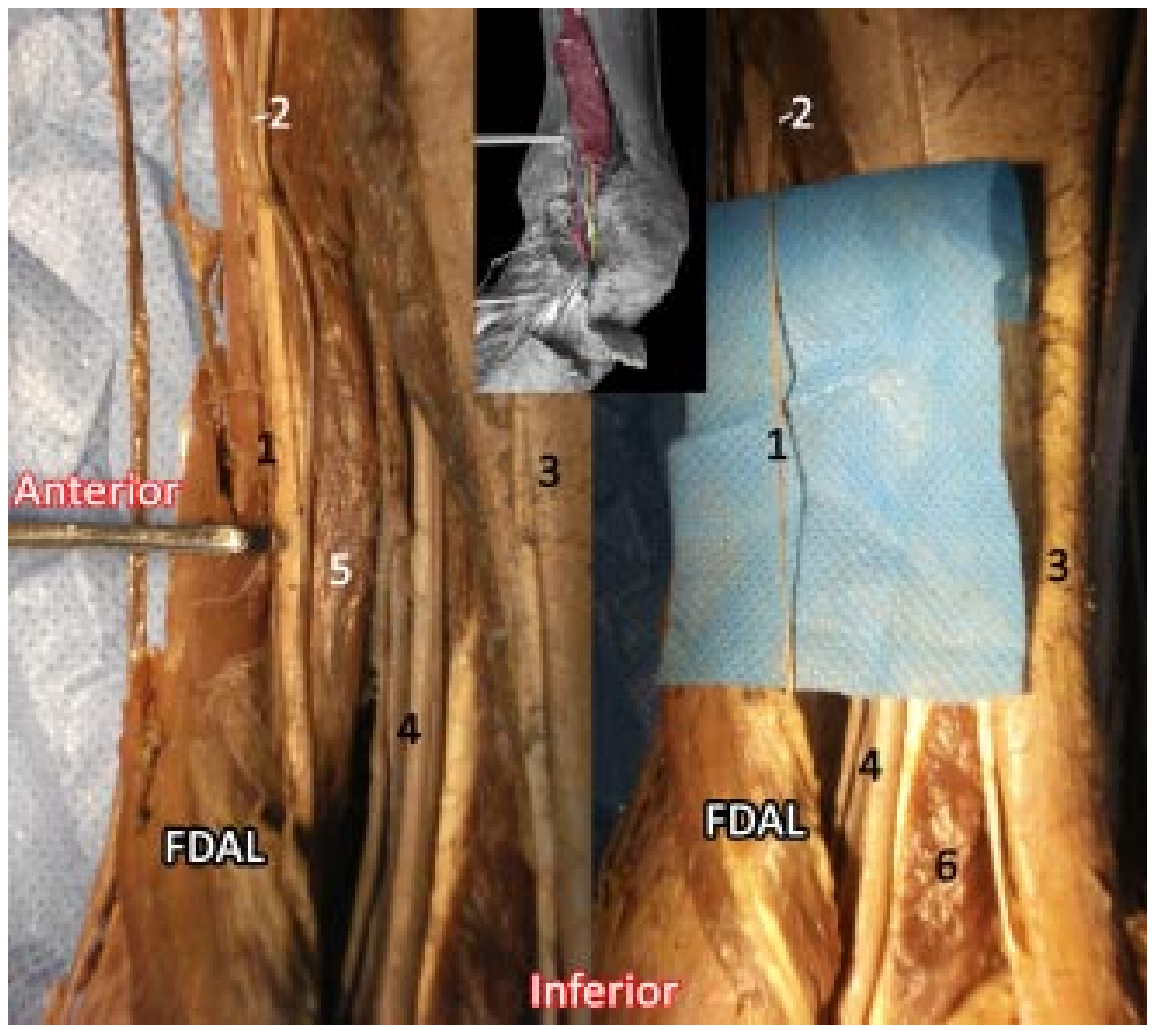

Fig. 6. Innervation of the AFDL (bilateral case, right leg). FDALM - flexor digitorum accesorius longus muscle; 1 . Inervation branch for the FDALM; 2. Branch from the tibial nerve; 3 . Calcaneal tendon; 4. Tibial posterior neurovascular bundle; 5. Flexor digitorum longus muscle; 6. Flexor hallucis longus muscle.

\section{DISCUSSION}

The FDALM is the most frequent muscular variation found in the posterior compartment of the leg. However, knowledge about it is scarce, and this can have clinical consequences.

In our research, we have described the discovery of a bilateral case of FDALM in a cadaver, with a $1.81 \%$ occurrence. Gümüs, alan \& Kalayciog $` l u ~(2000)$ have also described the discovery of a bilateral case, occurring in $3.33 \%$ of 60 specimens. Meanwhile, Nathan et al. have found 2 cases of bilateral FDALM in 100 legs, with a $4 \%$ occurrence; and del Sol et al. have found 1 bilateral case, occurring in $1.33 \%$ of 150 specimens (Table III).

If we consider them unilateral variations, occurrence in our research should be $2.72 \%$, arising from a total of 110 legs. Our data are similar to findings presented by Driver and Denison and del Sol et al., with $1.80 \%$ and $2.00 \%$, respectively. Wood has also described the occurrence of this muscular variation in $3.92 \%$ of cases. Higher percentages of FDALM occurrence have been described by Nathan $e t$ al. $(14.00 \%)$ (Table III).

Regarding its morphological disposition, the FDALM presents variations mainly in relation to its origin and insertion. Rosenmüller (in LeDouble, 1897) has identified muscular fibers originating as a tendon from the fibula and ending within adipose tissue at the calcaneal tendon and ankle level. On the other side, Knott (in LeDouble) has observed it ending at the os calcis or flexor hallucis muscle; and Reinhardt has described it originating at the os calcis and ending at the quadratus plantae muscle. According to Gantzer and Ringhofer (in Hwang \& Hill et al.), this supernumerary muscle is originated at the fibula; according to Macalister (in Turner), Kolliker (in LeDouble), Wood, Testut, and Morestin (in LeDouble), at the peroneus brevis muscle; Theile (in Hwang \& Hill et al.) has described its origin at the tibia; Turner has described its origin both at the tibia's medial margin and at the fibula and its end at the anterior surface of the quadratus plantae muscle; Davies - Colley and Dalton have observed other sites (in LeDouble). Wood and Prenant have described this supernumerary muscle to be originated at three different sites (Wood; LeDouble).

In reference to the embryonic origin of this muscular variation, many authors have suggested in a different manner that it is related to the quadratus plantae muscle; that is why it is also referred to as 'quadratus plantae 
OTTONE, N. E.; TEJEDOR, M; BLASI, E.; MEDAN, C. D.; FUENTES, R. \& DEL SOL, M. Morphological description of the flexor digitorum accessorius longus muscle and its clinical significance. Int. J. Morphol., 33(2):611-619, 2015.

Table III. Investigations comparisons of the presence of the flexor digitorum accessorius longus muscle - FDALM.

\begin{tabular}{|c|c|c|c|c|c|c|}
\hline \multirow[b]{2}{*}{ Authors } & \multirow[b]{2}{*}{ Total n } & \multicolumn{5}{|c|}{ Flexor digitorum accessorius longus muscle - FDALM } \\
\hline & & $\begin{array}{c}\text { Total n } \\
\text { FDALM * }\end{array}$ & Unilateral & Bilateral & 1 Head & 2 Heads \\
\hline Present study & 110 & $3(2.72 \%)$ & $1(0.91 \%)$ & $1(1.81 \%)$ & 2 & 1 \\
\hline del Sol etal. & 150 & $3(2.00 \%)$ & $1(0.67 \%)$ & $1(1.33 \%)$ & 1 & 2 \\
\hline Wood & 204 & $8(3.92 \%)$ & $8(3.92 \%)$ & - & - & - \\
\hline Driver \& Deninson & 214 & $4(1.87 \%)$ & $4(1.87 \%)$ & - & - & 4 \\
\hline Nathan et al. & 100 & $14(14.00 \%)$ & $12(12 \%)$ & $2(4 \%)$ & 6 & 8 \\
\hline Gümüsalan \& Kalaycioglu & 60 & $2(3.33 \%)$ & - & $1(3.33 \%)$ & - & 2 \\
\hline
\end{tabular}

*including bilateral FDALM, considering each FDALM individually

accessorius' muscle. According to Wood, its occurrence would be related to a persistent superior origin of the quadratus plantae muscle, represented in the deep muscular layers of the leg by the fibular and tibial fascicles that have reached the sole of the foot. Other authors have explained this muscular variation in relation to the embryonic development of same quadratus plantae muscle which initially would originate from the medial retromalleolar region and sometimes from the flexor hallucis longus muscle, which would progress towards the calcaneum during development. According to Driver and Denison, this anomaly is a remnant of an ancestral muscle of considerable size. Its persistent portion would be the quadratus plantae muscle (Buckingham), while the FDALM would correspond to the regressive part of that muscle (Yüksel et al.). Meanwhile, Nathan et al. have considered it a remnant of a portion of the flexor hallucis longus muscle that has gradually migrated from the leg to the sole to become the medial head of the quadratus plantae muscle. The theory of muscle migration from the leg into the sole is also supported by Winckler and Giacomo, who believe that variations in the morphology of the FDALM are associated to the varying processes of migration. Lewis (in Georgiev et al.) has stated that the medial head of the FDALM is associated to a new development originating from the deep head of the flexor digitorum brevis or flexor hallucis longus muscles; while the lateral head of this muscle is homologous to it occurrence in other mammals. These latter statements support the theory that the medial head of the FDALM is recent in the phylogeny because of its high variability, its lateral head being much more frequent and persistent, and defining the unilateral shape of the FDALM, as we have described in our research (in Georgiev et al.).

Athavale et al. (2012) also support that the occurrence of this muscle may arise from a need to improve the grip of the midfoot. This theory is supported by digitrigrade posture of animals that stand on the lateral margin of their feet. This would determine the occurrence of this voluminous muscle in the medial portion of the human foot to achieve the human plantigrade posture. However, he also argues that an electromyography would be needed to confirm this theory.

FDAL muscles with one or two fascicles originated from the same bone (tibia or fibula) or from both bones have also been described. (Turner; Wood; Macalister; Testut; Driver \& Denison; Lewis; Nidecker et al.; Bergman et al.; Erickson et al.; Sammarco \& Stephens; Yüksel et al.; Buckingham et al.; del Sol et al.; Gümüs,alan \& Kalayciog $`$ lu; Kurtoglu et al.; Jaijesh et al.; Athavale et al.). The most common origin for the FDALM is the fibula. In our bilateral case, the FDALM in the right leg originates from the medial margin of the tibia, while the FDALM on left leg originates from the medial surface of the fibula. In addition, the origin more frequently occurs together with the flexor digitorum longus muscle (Buckingham et al.).

Regarding the nervous supply of this muscle, we found it in one case (right leg of the bilateral case) from the calcaneal branches originated directly from the tibial nerve (Figure 6). Similarly, the innervation of the FDALM through tibial nerve is described by Georgiev et al.

The FDALM is the anatomical variation most frequently found in the posterior muscular compartment of the leg, but it does not always bear the same morphology. This will determine its contribution to the region's pathologies. It originates in the lower third of the leg and depending on its itinerary to the foot, it related closely to the vascular and nervous elements in the region, with the possibility of causing a compression neuropathy (Lewis; Erickson et al.; Sammarco \& Stephens; Yüksel et al.; Buckingham et al.; del Sol et al.; Kurtoglu et al.). In this regard, many different factors have been described as causes of tarsal tunnel syndrome, such as trauma, fibrosis, synovitis, rheumatoid arthritis, hallux valgus, neurinomas, and fractures, among others. These compressions are characterized by paresthesia and pain in the limb (Buckingham et al.; Eberle et al., 2002). Also, the occurrence 
of this muscular variation represents one of the possible causes of tarsal tunnel syndrome (authors). Samarco \& Stephens argue that this pathology occurs when the FDALM crosses the surface of plantar nerves, and do not cause any problem if it crosses these elements deeply (Buckingham et al.; LeDouble). However, we consider that the possible neurovascular compression will depend not only on location but also on the morphology of the FDALM - from a single tendon to a real muscular body. So neurovascular elements can also be compromised by constriction if the muscle crosses the neurovascular bundle deeply, but the muscle itself is a voluminous muscular body. In the cases we have described, especially in the right FDALM of the bilateral case, the voluminous muscular body originates a sort of arch for the neurovascular bundle, which may become a site of possible neurovascular compression.
During physical examination, the FDALM can be observed as a voluminous structure that stands out between the tibia and the calcaneal tendon, not allowing the patient to perform dorsiflexion. This can be confirmed by imaging studies, especially MRI, when observing a ring around ankle and leg muscles (Eberle et al.). To solve this issue, reports have been published based on cases of tarsal tunnel syndrome whose treatment has been the complete resection of the muscle of anomalous tendons (Buckingham et al.).

Finally, knowing the possible occurrence of this anatomic variation in patients who suffer pathologies in the ankle and foot regions, such as the tarsal tunnel syndrome, as this is the most frequent muscle variation, is crucial in order to make a correct diagnosis and subsequent clinical and surgical treatment.

OTTONE, N. E.; TEJEDOR, M; BLASI, E.; MEDAN, C. D.; FUENTES, R. \& DEL SOL, M. Descripción morfológica del músculo flexor largo accesorio de los dedos y su significancia clínica. Int. J. Morphol., 33(2):611-619, 2015.

RESUMEN: El músculo flexor largo accesorio de los dedos es una variación anatómica poco frecuente que se produce en la pierna y el pie. Esta variación fue descrita por primera vez por Meckel en 1818. El músculo se origina de la tibia o de la fíbula y se extiende desde ésta hacia el músculo cuadrado plantar o al músculo flexor largo de los dedos, cruzando el canal retromaleolar medial manteniendo una estrecha relación con los vasos tibiales posteriores y el nervio tibial. Fueron disecadas 110 piernas de cadáveres de individuos adultos, de ambos sexos, de raza caucásica, conservados previamente en solución de formalina al 5\%. Desarrollamos una técnica de disección en "2 tiempos" para localizar el músculo flexor largo accesorio de los dedos, esencial para el abordaje seguro y exitoso de los procedimientos quirúrgicos realizados en la región. Se describen tres casos de músculo flexor largo accesorio de los dedos. Dos de ellos, bilaterales encontrados en un cadáver. El conocimiento de esta variación muscular, su origen embrionario y la posibilidad de encontrarlo durante los estudios clínicos y procedimientos invasivos en la pierna y en el pie adquiere importancia en el diagnóstico diferencial de las patologías compresivas.

PALABRAS CLAVE: Flexor largo accesorio de los dedos; Patologías compresivas; Variación anatómica.

\section{REFERENCES}

Athavale, S. A.; Geetha, G. N. \& Swathi. Morphology of flexor digitorum accessorius muscle. Surg. Radiol. Anat., 34(4):36772, 2012.

Bergman, R. A.; Thompson, S. A. \& Afifi, A. K. Opera. Illustrated Encyclopedia of Human Anatomic Variation. 2014. Available in: http://www.anatomyatlases.org/AnatomicVariants/ AnatomyHP.shtml

Buckingham, R. A.; Winson, I. G. \& Kelly, A. J. An anatomical study of a new portal for ankle arthroscopy. J. Bone Joint Surg. Br., 79(4):650-2, 1997.

del Sol, M.; Olave, E. \& Gabrielli, C. Frecuencia e importancia anátomo clínica del músculo accesorio del músculo cuadrado plantar. Rev. Chil. Anat., 18(2):279-82, 2000.

618
Driver, J. R. \& Denison, A. B. The morphology of the long accessorius muscle. Anat. Rec., 8(6):341-7, 1914.

Eberle, C. F.; Moran, B. \& Gleason, T. The accessory flexor digitorum longus as a cause of Flexor Hallucis Syndrome. Foot Ankle Int., 23(1):51-5, 2002.

Erickson, S. J.; Quinn, S. F.; Kneeland, J. B.; Smith, J. W.; Johnson, J. E.; Carrera, G. F.; Shereff, M. J.; Hyde, J. S. \& Jesmanowicz, A. MR imaging of the tarsal tunnel and related spaces: normal and abnormal findings with anatomic correlation. A. J. R. Am. J. Roentgenol., 155(2):323-8, 1990.

Georgiev, G. P.; Jelev, L.; Kinov, P. \& Vidinova, N. K. A rare instance of an accessory long flexor to the second toe. Int. J. Anat. Var., 2:108-10, 2009. 
OTTONE, N. E.; TEJEDOR, M; BLASI, E.; MEDAN, C. D.; FUENTES, R. \& DEL SOL, M. Morphological description of the flexor digitorum accessorius longus muscle and its clinical significance. Int. J. Morphol., 33(2):611-619, 2015.

Gümüsalan, Y. \& Kalaycioglu, A. Bilateral accessory flexor digitorium longus muscle in man. Ann. Anat., 182(6):573-6, 2000 .

Hwang, S. H. \& Hill, RV. An unusual variation of the flexor digitorum accessorius longus muscle-its anatomy and clinical significance. Anat. Sci. Int., 84(3):257-63, 2009.

Jaijesh, P.; Shenoy, M.; Anuradha, L. \& Chithralekha, K. K. Flexor accessorius longus: A rare variation of the deep extrinsic digital flexors of the leg and its phylogentic significance. Indian $J$. Plast. Surg., 39(2):169-71, 2006.

Kurtoglu, Z.; Uluutku, M. H.; Can, M. A. \& Onderoglu, S. An accessory flexor digitorum longus muscle with high division of the tibial nerve. Surg. Radiol. Anat., 23(1):61-3, 2001.

LeDouble, A. F. Traité des Variation du Système Musculaire de l'Homme et Leur Signification au Point de l'Anthropologie Zoologique. Paris, Libraire C. Reinwald, Schleicher Freres, 1897.

Lewis, O. J. The comparative morphology of M. flexor accessorius and the associated long flexor tendons. J. Anat., 96:321-33, 1962.

Macalister, A. Additional observations on muscular anomalies in human anatomy (third series), with a catalogue of the principal muscular anomalies hitherto published. Trans. Roy. Irish Acad. Sci., 25:1-134, 1875.

Nathan, H.; Gloobe, H. \& Yosipovitch, Z. Flexor digitorum accessories longus. Clin. Orthop. Relat. Res., (113):158-61, 1975.

Nidecker, A. C.; von Hochstetter, A. \& Fredenhagen, H. Accessory muscles of the lower calf. Radiology, 151(1):47-8, 1984.

Sammarco, G. J. \& Stephens, M. M. Tarsal tunnel syndrome caused by the flexor digitorum accessorius longus. A case report. $J$. Bone Joint Surg. Am., 72(3):453-4, 1990.

Sooriakumaran, P. \& Sivananthan, S. Why does man have a quadratus plantae? A review of its comparative anatomy. Croat. Med. J., 46(1):30-5, 2005.

Testut, L. Les Anomalies Musculaires Chez L'Homme Expliques par L'Anatomie Comparée. Paris, Masson, 1884.

Turner, W. On variability in human structure, with illustrations, from the flexor muscles of the fingers and toes. Trans. Roy. Soc. Edinb., 24:175-89, 1867.

Yüksel, M.; Onderog `lu, S.; Yener, N. \& Yüksel, E. An accessory flexor digitorum longus muscle. Acta Anat., 148(1):62-4, 1993.

Wood, J. Variations in human myology observed during the winter session of 1867-68 at King's College, London. Proc. R. Soc. Lond., 16:483-525, 1868.

\section{Correspondence to: \\ Prof. Nicolás Ernesto Ottone \\ Faculty of Dentistry \\ Universidad de La Frontera \\ Manuel Montt 112 \\ Temuco - CHILE}

Email: nicolas.ottone@ufrontera.cl

Received: 03-02-2015

Accepted: 22-04-2015 